\title{
The Directions of Evaluation of Innovative Products' Implementation in Construction and Developer Organizations
}

\author{
Oksana Papelniuk ${ }^{1, *}$ \\ ${ }^{1}$ Moscow State University of Civil Engineering,26, Yaroslavskoye shosse, Moscow,129337, Russia
}

\begin{abstract}
The article describes the directions of evaluation of innovative products' implementation in construction and developer organizations. The author analyzes the effects and offers the criteria for evaluation of efficiency of implementation of an innovative products. It is concluded that this evaluation should include estimation of efficiency of all participants of implementation of an innovative product at all development stages and project implementation during construction and operation of an object, thus the corresponding approach is offered.
\end{abstract}

\section{Introduction}

Task of increase in level of innovative activity in a construction and development and management of factors on its development purchased the special importance now. Reproduction of innovations requires forming and development of the adequate controlling mechanism by these processes representing set of methods and management tools innovative cycles for providing its continuity, sufficient dynamism and required scale. In relation to the construction and developer organizations an important role is played at the same time by organizational procedures of management of innovative projects in implementation of innovative products and technologies where the central role in case of decision making about implementation is played by assessment with reasons for efficiency of their implementation.

For successful solving of questions of an effective objective of the conducted researches it was necessary to consider essence of innovative activities first of all.

About two tens of determination of essence of innovations are revealed. Most fully the innovation can be determined as follows: an innovation (an innovation, an innovative product) - the result of innovative activities which received the embodiment in the form of a new product, service, technology and/or a new organizational and ecological form, having clear high-quality advantages when using in designing, production, sale, consumption and utilization of the products providing additional in comparison with the previous product, service, technology and/or an organizational and economic form economic (economy of costs or an additional profit) and/or public benefit. It is visible that this determination of an

"Corresponding author: oksana-17@mail.ru 
innovation though very extensive, but it in rather complete measure discloses essence of innovatics.

\section{Methods}

The corresponding legal acts concerning an economic reform of the national economy of the country, objective economic laws of development of the market relations, works of prominent Russian and foreign scientists formed theoretical and methodological base [1].

In the course of the research methods of strategic management, system approach, a comparison method in case of products efficiency evaluation are used, the existing methodical provisions of an efficiency evaluation of projects.

Reproduction of innovations in enterprise subjects depends on very many factors. In the most general case the most significant of them are given in the figure 1 .

It is visible that there is a lot of conditions and will consider them absolutely not easy and to estimate in case of development and implementation of each specific innovative projects.

Until recently innovative products and innovative processes didn't gain due distribution including in a construction field of activity, and mainly because of limitation of the resources allocated for development of this field of activity in the country.

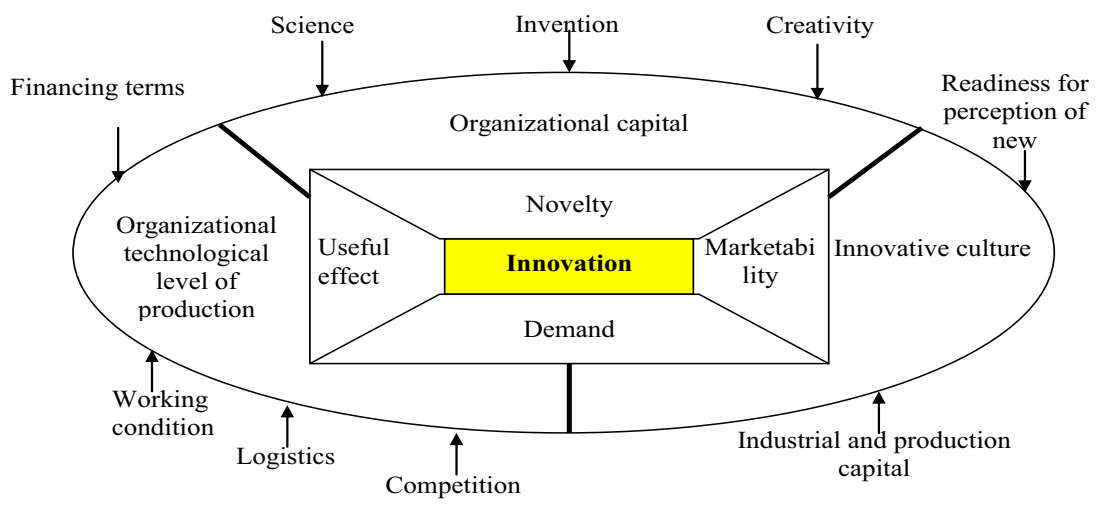

Fig. 1. Main conditions of formation of reproduction of innovation

For descriptive reasons we will give the listed functions of innovative management in fig. 2 .

In case of development of the system of management of the innovative project its environment is considered. It is set of the external and internal factors influencing project implementation[2,3].

In the most general case the factors of the internal and external environment exerting impact on indicators of activities of the contractor of the innovative project are provided in fig. 3.

In a construction new technologies and new construction materials became the most demanded. But, unfortunately, so far results of scientific and technical activities so far in the main weight didn't become the commercial product ready for production and effective implementation[4].

Today to become the main criterion for evaluation of new construction materials and technologies of a construction not compliance to requirements of technical regulations. It is accepted to differentiate two types (two forms) of technological innovations: product and process. 


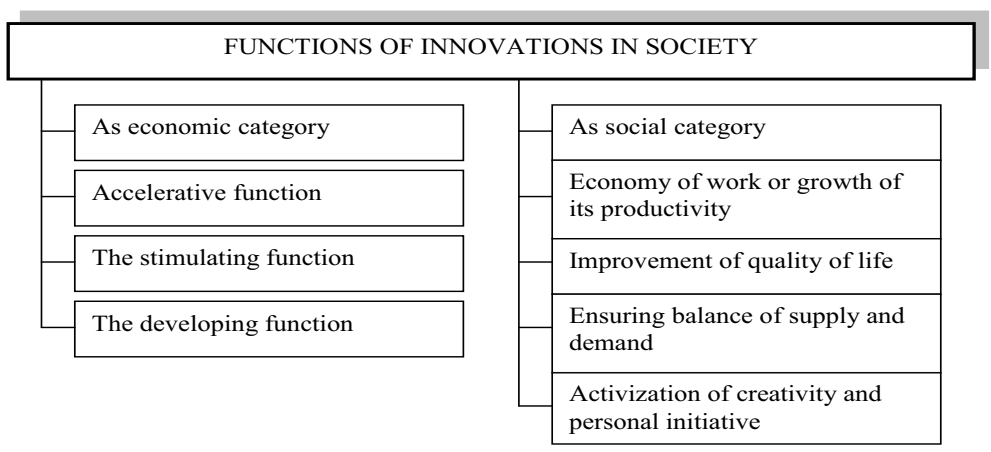

Fig. 2. Functions of innovations in society

Product innovations - implementation of new or advanced products, and process innovations are a development of new or advanced products of production organization. Production in a process innovation is impossible when using of the equipment which is available in the organization or the applied production methods. Therefore first of all it is necessary to make a choice - on what type of an innovation (product or process) it is necessary to be guided when carrying out innovative work in the construction organization $[5,6]$. In the basic plan both forms and even at the same time can be used. But nevertheless first of all it is recommended to use product innovations. It is still very important to stop on consideration of types of implementation of an innovative product in the construction organization. It is possible to allocate 2 methods of implementation:

- the new innovative product is developed and takes root in the construction organization;

- the new innovative product is developed in other accounting entity (research institution, design office, in another, and usually large construction organization) and already directly takes root in the construction organization.

Practice specifies that the second type of implementation of a new innovative product is the most characteristic of the construction organizations working at this stage of development of market economy of Russia[7].

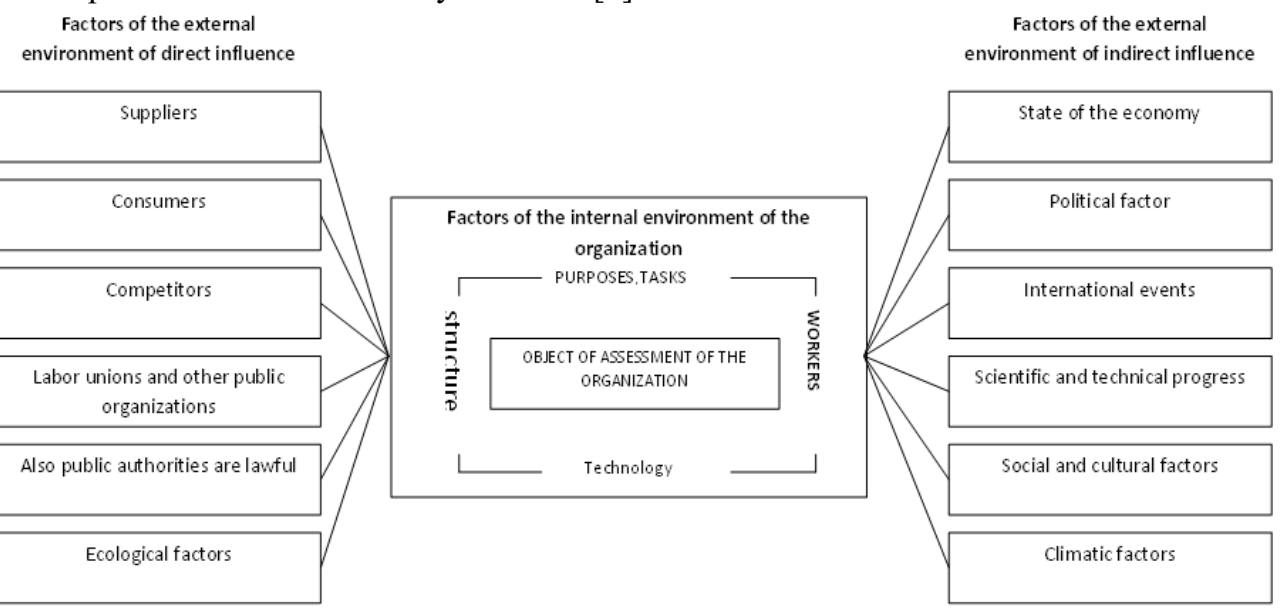

Fig. 3. The factors of the internal and external environment exerting impact on indicators of assessment of activities of the participating organization as the investor and the contractor for development and project implementation. 
In all cases implementation of any innovative product in the construction organization should be considered as development and implementation of some project as project management on the essence is universal tools[8].

Success of implementation of innovations in the construction organization, first of all, depends on the following factors:

- scientific and technical potential and industry, as bases of the construction organization;

- technological base of the construction organization;

- availability of main types of resources;

- availability and opportunities of receipt of additional investments;

- already developed management system in the construction organization.

The choice of a proper correlation and use of the considered factors, and also close interrelation through a management system between an innovative, productive and marketing activity will also influence the choice of a form of innovative activities in the organization. In Russia it is entered for a long time and universal tools for an efficiency evaluation of investment projects which are called "Methodical recommendations about an efficiency evaluation of investment projects are practically used. Though this document is called "Methodical recommendations", but it is official and it needs to be used practically in all cases[9,10].

Entered to carry out adaptation of the settlement processes of efficiency of application of all investment projects given in Methodical instructions to development of management decisions for an efficiency evaluation of application of innovative products (new construction materials) in the construction organizations to a task of the conducted researches. As basic criteria for evaluation of results and costs of implementation of a new innovative product shall be:

- profit surplus;

- growth in volumes of sales;

- performance improvement;

- expense reduction of materials and labor costs;

- expansion of the market and receipt of benefits in competitive struggle;

- degree of fitness of new developments to the existing means of production, materials, organizational structures;

- promotional expenses and sale;

possibility of increase in sales volume in the future.

\section{Results}

Analyzing the given criteria for evaluation of efficiency of implementation of an innovative product it is possible to make the conclusion that it is necessary to estimate efficiency of many participants of implementation of an innovative product and it is possible at all development stages and project implementation on a construction and operation of an object. In the most general case as the main estimative indicator in case of development and sale of a new product the indicator of a ratio of annual profit to the investment capital can be used:

$$
E ; K=(V-P-F-A): K
$$

where: 
E - annual profit; K - investment capital; V - sales volume in a year; $\mathrm{P}$ - costs of production in a year on the made new products; F - annual costs on researches and developments on the made new products; $\mathrm{A}$ - annual charges on sale and management.

The efficiency evaluation of production and sale of a new innovative product on the considered formula for the construction organization and for the customer, can't take place and mainly because the construction and operation of the constructed objects can't be estimated by one year. Also other approach in the construction organization acting as a developer and the seller of a new innovative product can be used. The so-called indicator of profitability calculated taking into account costs for researches and development, development of production and promotion of an innovation for the market is its cornerstone.

$$
P=\left(E_{\mathrm{H}} \cdot E_{\mathrm{K}} \cdot V_{\mathrm{Y}} \cdot \mathrm{R}_{\mathrm{k}} \cdot P_{P s .}\right):(\mathrm{Pe}+\mathrm{F}+\mathrm{A}),
$$

where: Ен - probability of scientific success, \%; Ек - probability of commercial success, $\%$; Vy - annual sales volume; Rk- unit price; Pps- period of steady sale; $\mathrm{Pe}$ - espenses of production; F - costs of a research and development; A - cost of sale and advance of production.

It is visible that this form of assessment in a construction can be applied, though not in all cases. But as in case of implementation of a new construction material in case of a construction, most often, the effect is gained not at a construction stage, and later, this effect can be estimated on value added (net production) received for the realization account of an innovation in the sphere of its production (creation and use) per a year which can be determined by a formula:

$$
\mathrm{DC}(\mathrm{A})_{1}=T \mathrm{P}_{1}-M_{1}
$$

where: $\mathrm{DC}(\mathrm{A})_{1}$ - value added in a year; $\mathrm{TP}_{1}$ - amount of products made for the realization account of an innovation per a year in cash; $\mathrm{M}_{1}$ - material costs on production per a year in cash. Volume of production (including depreciation) for the realization account of an innovation is determined by summing of annual amounts of net production.

\section{Discussions}

In essence from this economic prerequisite it is necessary to estimate in most cases cost efficiency of implementation of a new construction material in the construction organization. As the effect in case of implementation of new construction materials can be most often gained already when using of the object constructed and put in operation, and the effect of application shall be estimated with a scope of some usage time of the constructed object. Therefore we recommend to use option of an efficiency evaluation of application of a new construction material when constructing facilities with use of Methodical recommendations about an efficiency evaluation of investment projects. As is well-known these recommendations are universal and officially the entered tools.

\section{Conclusion}

Besides very simple method of comparison can be used. It is based on comparison of economic, technical, ecological, organizational and construction indicators when replacing an old product on new and, most often, innovative. It is the simplest method, but in case of its use it is already necessary to have someone the received indicators, initial for comparison. 


\section{References}

1. L.Ustinovicius, R.Rasiulis, L.Nazarko, T.Vilutienè , M.Reizgevicius. Procedia Engineering, 122,166-171 (2015)

2. M. T. Hannan. Change Management: a reader (Publishing House of the Executive. wk. Management, St. Petersburg, 2010)

3. A.D. Ishkov, M.Yu. Mishlanova, K.P. Grabovyi. International Journal of Applied Engineering Research. 11( 3), 1676-1679, 2016.

4. A.C. Aurora Teixeira, S.S. AnabelaQueirós. Research Policy, 45, 1636-1648 (2016)

5. Sborshchikov S.B., Lazareva N.V., ZharovYa.V. Vestnik MGSU, 6, 165-171 (2014)

6. E.K. Chirkunova, E.E. Kireeva, A.D. Kornilova, J.S. Pschenichnikova. Procedia Engineering, 153, 112-117 (2016)

7. P.G. Grabovyi, I.P. Avilova, A.V. Sharapova, Life Science Journal, 11, 1097 (2014)

8. I.G. Lukmanova, A.G. Korolyov, E.V. Nezhnikova, Project Management, (MGSU, Moscow, 2013)

9. V. Khmel, S. Zhao. IATSS Research, 39, (2), 138-145 (2016)

10. D.N. Silka, Life Science Journal, 7, 310-313 (2014) 